\title{
Development and implementation of Intelligent Soot Blowing Optimization System for TNB Janamanjung
}

\author{
Taneshwaren Sundaram ${ }^{1}$, Firas Basim Ismail ${ }^{1 *}$, Prem Gunnasegaran ${ }^{1}$, and Pogganeswaren \\ Gurusingam $^{1}$ \\ ${ }^{1}$ Power Generation Unit, Institute of Power Engineering (IPE), Universiti Tenaga Nasional, 43000 \\ Kajang, Selangor, Malaysia.
}

\begin{abstract}
With an ever increasing demand for energy, Malaysia has become a nation that thrives on solid power generation sector to meet the energy demand and supply market. In a coal fired power plant, soot blowing operation is commonly used as a cleaning mechanism inside the boiler. There are many types of sequence available for this soot blowing operation. Hence, there is no efficient ways in utilizing the soot blowing operation to enhance the efficiency of boiler. Soot blowing optimization requires specific set of data preparation and simulation in order to achieve the best modal. Computational Fluid Dynamics (CFD) is used to model a 700MW supercritical boiler, whereby parameters with effect to soot blowing operation is studied. Two different boiler condition is studied to analyze parameters in a clean and faulty boiler. Artificial Neural Network (ANN) is used to train neural network modal with back propagation method to determine the best modal that will be used to predict soot blowing operation. Combination of neural network different number of neurons, hidden layers, training algorithm, and training functions is trained to find the modal with lowest error. By improving soot blowing sequence, efficiency of boiler can be improved by providing best parameter and model. This model is then used as a reference for advisory tool whereby a Neural Network Predictive Tool is suggested to the station to predict the soot blowing operation that occurs.
\end{abstract}

\section{Introduction}

The combustion of coal-fired power plant in Malaysia causes build-up of combustion deposits such as soot, ash and slag in the boiler. Combustion deposit generally decreases the efficiency of the boiler by reducing heat transfer. To maintain boiler efficiency, the surfaces in boiler are periodically cleaned by directing cleaning medium called soot blowers. Soot blowers are a cleaning mechanism that uses steam to blow of boiler flue gas circuit at different points. It carries out periodic cleaning to the parts that are exposed to ash deposits such as furnace, super heater, re heater, and economizer. There are many power plants in the world that uses an intelligent soot blowing system that is vastly becoming an important

*Corresponding author : Firas@,uniten.edu.my 
system during boiler operations. This is because an optimized soot blowing system will eventually increase the boiler efficiency $[1,2]$. This optimized system only allows the soot blowers to function when it is needed and in necessary location. It does not follow a specific interval or period for it to work. An intelligent soot accumulation monitoring system will provide the updated data during boiler operations [3, 4]. There is a tool to predict and measure soot accumulation in boiler. Besides, by predicting soot accumulation, soot blowing can take place when slagging occurs. Hence, the soot blowers will be activated and soot blowing system will operate at the affected areas. The rate of heat flux and heat transfer, especially in the furnace indicates the level of soot accumulation in the boiler. The main idea is to reduce the frequency of soot blowing and hence, reducing the steam consumption during soot blowing that will eventually increase the efficiency of boiler and reduce maintenance cost [5].

\section{Methodology}

The methodology is built based on the research made on most related works in literature review. There are three main phases that is constructed in this methodology are as follows:

Data Preparation $>$ Modelling $>$ Analysis and Advisory Tool

\subsection{Data preparation}

Data collection is a key part to identify and characterize each data. In order to run simulation, a specific data set is required. All the necessary data is taken from the Plant Information (PI) station in TNB Janamanjung.

\subsection{Modelling}

The most important phase of this paper is modelling. There are two different types of software used for modelling phase. For CFD, ANSYS V15 Fluent is used to simulate two different boiler conditions, clean (with soot blowing) and faulty (without soot blowing). For ANN, MATLAB is used to run the neural network and to find the best neural network modal for soot blowing operation [6].

\subsubsection{Computational fluid dynamics modelling}

The main objective of simulating both boiler conditions is to study the behaviour of process. The pre-modelled boiler modal is used to simulate the boiler conditions. Two separate runs have been performed in orders to obtain two sets of different data. These sets of data are compared and the behaviour of the boiler can be analysed. The simulation is ran for 5001000 iterations, hence the difference in data captured is tabulated.

\subsubsection{Neural network modelling}

The neural network basically contains 3 main layers, input, hidden layers and output. In feed forward network, the structure selection is done based on number of hidden layers, one hidden layer and two hidden layer with 1-10 number of neurons for each hidden layer. These different combination of structures will produce different output [7]. 


\section{Results and Discussion}

In this study, the results of CFD and ANN will be explained in more detail to get a clearer understanding about this project. The simulated data and contours from CFD is obtained with behaviour graphs of clean and faulty boiler. On the other hand, the results in form of RMSE values are tabulated and each input behaviour graph is portrayed for a clearer discussion.

\subsection{Comparison of clean and faulty boiler}

Through the analysis using Computational Fluid Dynamics (CFD), the factors that has been considered in soot blowing has been taken into account and simulated using this software. Throughout the analysis, two different sets of results have been obtained in clean and faulty boiler as shown in Table 1.

Table 1. Comparison of clean and faulty boiler

\begin{tabular}{|c|c|c|}
\hline Boiler Parameter & Clean Boiler & Faulty Boiler \\
\hline Pressure, $\mathrm{Pa}$ & 359,023 & 419,055 \\
\hline Temperature, $\mathrm{K}$ & 2708 & 2111 \\
\hline Heat Flux, $\mathrm{w} / \mathrm{m} 2$ & $5,020,528$ & $1,319,415$ \\
\hline Heat Transfer, w/m2.K & $7,052.88$ & $1,961.11$ \\
\hline Mass Imbalance, $\mathrm{kg} / \mathrm{s}$ & 0.008059487 & 0.02689896 \\
\hline
\end{tabular}

When soot blowing happens, the boiler is assumed as a clean boiler. When the fireball is formed and flue gas is produced, soot accumulation and slagging will take place in boiler [8]. These two conditions are taken into account to validate the boiler condition by using CFD. Before soot blowing takes place, the pressure in the boiler is higher compared to faulty boiler. This is because, before soot blowing, the boiler is in dirty condition whereby soot accumulation and slagging occurs in all parts of boiler. By consuming space in boiler, the pressure will increase in presence of soot. After soot blowing, after all the slagging is removed, the pressure of boiler can be reduced as shown in Table 1. The temperature also plays a huge part in maintaining the boiler efficiency. In a clean boiler, the temperature of is relatively high which is important in relating with heat transfer and heat flux. However, in a faulty boiler, the temperature is reduced into almost half as the soot accumulated in the boiler absorbs the heat produced in boiler. This will directly reduce the performance of the boiler. Hence, soot blowing operation and ensuring the boiler is in clean condition is important. Heat flux and heat transfer relate to each other. Before soot blowing, slagging causes the rate of heat flux and heat transfer to decrease as the soot accumulation will disrupt the surface contact between the walls [9]. Hence with soot blowing, there will be no disruption at the walls as there is no soot accumulation. As shown in Table 1, heat flux and heat transfer increases after soot blowing happens in a clean boiler. Lastly, mass imbalance is a great way to measure the amount of soot accumulated in boiler. In a clean boiler, the mass imbalance is figuratively steady and low. However in a faulty boiler, the mass imbalance increases drastically as shown in Table 1. This is because of soot accumulation occurrence in various parts of boiler. By soot blowing operation, the mass imbalance can be kept in an optimum value. 


\subsection{ANN results and analysis}

Construction of ANN consists of 2 different number of hidden layer, the first one would be with one hidden layer that has two different activation functions. The activation functions used in this project as stated previously are, Logsig (L), Tansig (T) and Purelin (P). Therefore the total combination that is present for one hidden layer with two activation functions is 9 . $\mathrm{L}+\mathrm{L}, \mathrm{L}+\mathrm{T}$ and $\mathrm{L}+\mathrm{P}$ are some examples with 10 number of neurons per combination. Besides, four different types of training algorithms are used, 'trainscg', 'trainlm', 'trainbfg' and trainrp'. However, for 2 hidden layer, three activation functions are used hence a total of 27 combinations to possible for this modal. These different combination will produce different RMSE with each simulation ran in MATLAB. After training all the combination, the combination with the lowest RMSE is considered the best ANN modal to be used in latter stages.

Table 2. Result summary of ANN

\begin{tabular}{|c|c|c|c|c|}
\hline $\begin{array}{c}\text { Training } \\
\text { Algorithm }\end{array}$ & Architecture & $\begin{array}{c}\text { Activation } \\
\text { Function }\end{array}$ & RMSE & $\begin{array}{c}\text { Number of } \\
\text { Iteration }\end{array}$ \\
\hline trainscg & 10HL1-6HL2 & $\mathrm{P}+\mathrm{T}+\mathrm{T}$ & 0.1561 & 86 \\
\hline trainlm & 9HL1-8HL2 & $\mathrm{L}+\mathrm{T}+\mathrm{T}$ & 0.1277 & 87 \\
\hline trainbfg & 7HL1-8HL2 & $\mathrm{P}+\mathrm{T}+\mathrm{T}$ & 0.1439 & 202 \\
\hline trainrp & 7HL1-9HL2 & $\mathrm{P}+\mathrm{T}+\mathrm{T}$ & 0.1539 & 139 \\
\hline
\end{tabular}

Table 2 summarizes the NN for 2 hidden layer for 4 different types of algorithm. The trainrp is the fastest training algorithm but produces an average RMSE. On the other hand, trainlm produces the best RMSE even though it took the longest to produce the RMSE. In addition, the 2 hidden layer NN produces better RMSE compared to 1 hidden layer. The graph in Figure 1 justifies the ANN combination modal which has the lowest RMSE value. Hence this modal will be used in future ANN predictive tool.

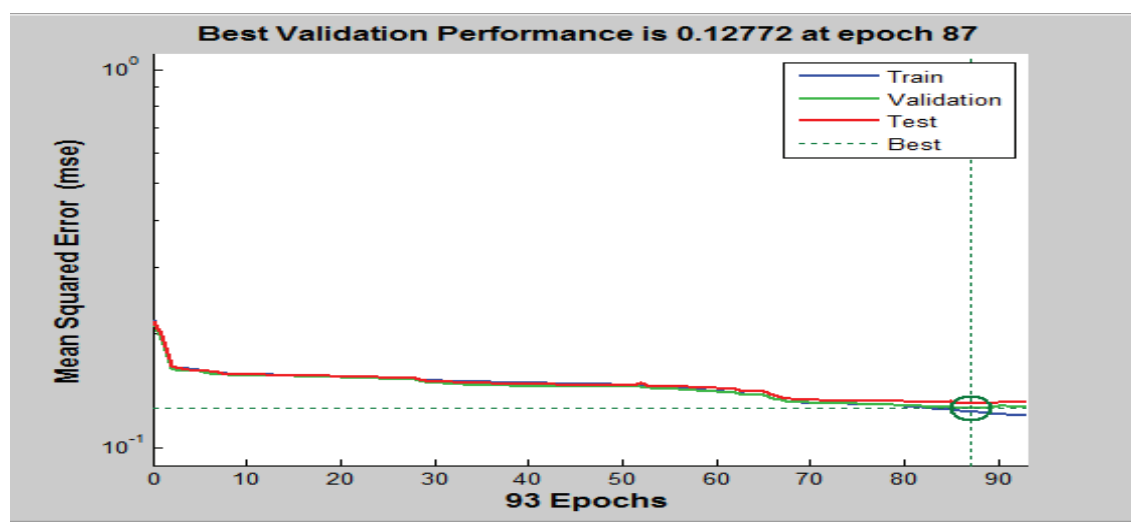

Figure 1. Best RMSE Performance Graph 


\section{Conclusion}

This journal focuses on studying the pattern and coming up with a solution that will benefit the station. Firstly, the main parameters are identified and studied to ensure the best soot blowing sequence can be identified. CFD simulation is done using ANSYS V15-FLUENT to study two different boiler conditions, clean (with soot blowing) and faulty (without soot blowing). CFD allows the interpretation of real performance during boiler operation. By performing this, the soot blowing sequence will determine how it will affect the daily boiler operation. Furthermore, the best combination of ANN model is the main aim to determine the best soot blowing sequence through simulation, training and validation. The training algorithm, activation functions, number of hidden layer and number of neuron in each hidden layer are ANN topologies that will produce the best validation. Different combinations will produce different result. Root Mean Squared Error (RMSE) is used to measure how effective is the combination. The combination with the lowest RMSE is the best neural network modal.

\subsection{Advisory tool}

Modal Predictive Control (MPC) is a process model which is used to predict the future evolution of the process to optimize control signal [10]. By implementing MPC in soot blowing operation, the soot blowing sequence for each day can be predicted and set during boiler operation. MPC provides an excellent arrays of suggestion to the system in order not to interrupt the boiler operations frequently. By using the best neural network modal obtained from ANN, the modal is used in PMC to find the best sequence of soot blowing in power plant. The optimization happens after the neural network modal is being analysed and implemented in different conditions and hence providing a sequence to the plant to operate the soot blowing operation shown by the yellow arrows in Figure 2. If there is some error between the plant and neural network modal, the data is sent back to the optimizer in order for detailed optimization as shown by orange arrows in Figure 2. This process is continued until the error margin between the neural network modal and plant is zero. Hence, the soot blowing operation in the power station is fully optimized hence, allowing boiler efficiency to be improved.

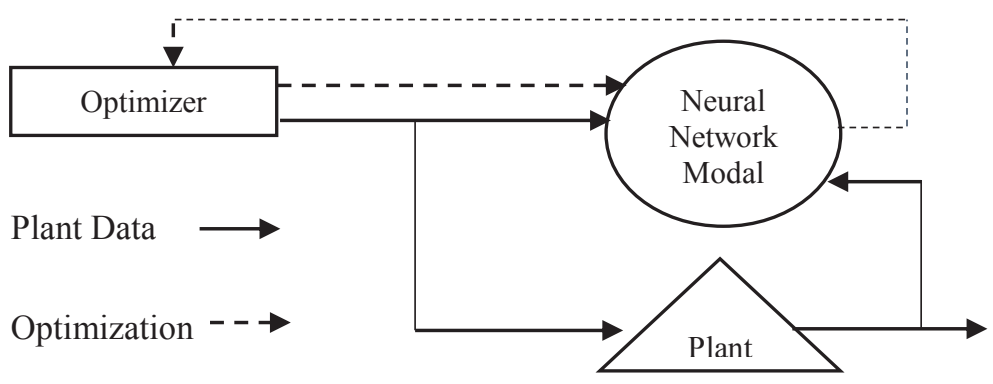

Figure 2. MPC modal

The authors would like to express our gratitude to the power generation unit, institute of power engineering Universiti Tenaga Nasional (UNITEN), TNB Janamanjung and Ministry of Higher Education (MOHE), Malaysia for the opportunity to sponsorship this corresponding research under the FRGS research fund with the project code 20160103FRGS. 


\section{References}

1. Emerson Process Management (2011). Ensure Efficient Sootblowing [Online]. Available:

http://www2.emersonprocess.com/siteadmincenter/PM\%20Power $\% 20$ and $\% 20$ Water $\%$ 20Documents/pws_003933.pdf

2. Powerclean Performance. Intelligent Sootblowing. [Online]. Available: http://www.babcock.com/library/documents/ps-388.pdf

3. Kansas City Power \& Light (KCP\&L) Hawthorn Generating Station.(2012) Boosting Efficiency with a Sootblowing Optimization System. [Online]. Available: http://www.powermag.com/boosting-efficiency-with-a-sootblowing-optimizationsystem/

4. B.Pena, L.I Diez and E. Teruel (May 2010). Soft-computing models for soot-blowing optimization in coal-fired utility boilers. [Online]. Available: http://www.sciencedirect.com.ezproxy.uniten.edu.my/science/article/pii/S1568494610 00102X

5. Shivaraj Kumar B. and Dr. N.S Venkatesh Gupta (2013). Effect of Smart Soot Blowing System in Boiler Furnace on Cycle Efficiency and Cost Saving. [Online]. Available: http://www.ijert.org/view-pdf/4396/effect-of-smart-soot-blowing-system-in-boilerfurnace-on-cycle-efficiency-and-cost-saving

6. Enrique Teruel, Cristobal Cortes, Luis Ignacio and Immaculada Arauzo (June 2005). Monitoring and prediction of fouling in coal-fired utility boilers using neural networks. [Online].

Available: http://www.sciencedirect.com.ezproxy.uniten.edu.my/science/article/pii/S0009250905 003283

7. Hugo Calisto, Nelson Martins and Naim Afgan (2007) - CFD and Neural Network based expert system for boiler performance [Online] Available: http://dc.engconfintl.org/cgi/viewcontent.cgi?article=1059\&context=heatexchanger20 07

8. Bhatt Samik (2014) - Analysis of Clinker Formation Region \& Soot Blower Optimization Using CFD Analyis [Online] Available: http://www.ijetae.com/files/Volume4Issue3/IJETAE_0314_111.pdf

9. Zhanhua Ma, Felicia Iman, Pisi Lu, Rod Sears, Lingbu Kong, A.S. Rokanuzzaman, Donald P. McCollar and Steven A. Benson (2007) - A comprehensive slagging and fouling prediction tool for coal-fired boilers and it's validation [Online] Available: http://www.academia.edu/5297900/A_comprehensive_slagging_and_fouling_predicti on_tool_for_coal-fired_boilers_and_its_validation_application

10. Modal Predictive Control Toolbox [Online]. Available: https://www.mathworks.com/products/mpc.html [Accessed 29 January 2016] 